\title{
The Importance of Friction Coefficient between Vehicle Tyres and Concrete Safety Barrier to Vehicle Rollover - FE Analysis Study
}

\author{
Jovan Trajkovski* - Miha Ambrož - Robert Kunc \\ University of Ljubljana, Faculty of Mechanical Engineering, Slovenia
}

The most important mechanical factors in an impact scenario of a vehicle into a concrete safety barrier are vehicle speed, the impact angle, the static stability factor of the vehicle as well as the concrete safety barrier design and conditions. Concrete safety barriers (CSBs) are primarily designed to minimize vehicle damage by allowing a vehicle to be lifted when riding up on the lower slope and then redirected back onto the road. In some cases, though, the vehicle-CSB contact might end with a rollover, often with fatal consequences. To reduce the rollover risk, different concrete barrier shapes were designed in the past, while omitting the importance of the friction coefficient between the tyre and barrier. Therefore, the aim of this paper is to research and emphasize the importance of the friction coefficient between vehicle tyres and a CSB in rollover accidents. For that purpose, a series of finite element analyses were performed using different values of the friction coefficient between vehicle tyres and a CSB. Experimental measurements of the coefficient of friction between the rubber and CSB blocks of different surface were additionally performed in dry and wet conditions in order to examine the real onsite friction characteristics. The results show that the coefficient of friction can have a crucial impact in vehicle rollover scenarios and should therefore be kept as low as possible by the CBS manufacturers and maintainers.

Keywords: concrete safety barrier, rollover, friction, simulation, finite element method

Highlights
- $\quad$ Vehicle-concrete safety barrier (CSB) crash analyses were performed using finite element models.
- $\quad$ Vehicle tyres-CSB coefficient of friction has a significant impact on a vehicle rollover.
- Vehicles with higher centre of gravity are prone to rollover upon collision with common CSBs.

\section{O INTRODUCTION}

According to the World Health Organization (WHO), over 3,400 people die on the world's roads every day and tens of millions of people are injured or disabled every year, $90 \%$ of which belong to low income countries [1]. In the European (EU) countries, the number of road deaths $(55,000)$ has been reduced by $43 \%$ between 2001 and 2010 and additionally reduced by $17 \%$ until 2015 [2]. After two years of stagnation, the number of deaths was reduced again in 2016 by $2 \%$. Although the European roads are the safest in the world [2], a lot more has to be done to achieve the "vision zero" in road fatalities.

One aspect of traffic safety assurance is separating the vehicles driving in opposite directions by means of traffic barriers providing physical lane separation. An ideal traffic barrier would redirect a vehicle back into its traffic lane safely enough to allow the driver to take control of the steering, avoiding secondary accidents. According to Gabler and Gabauer [3], in vehicle-totraffic barrier crashes, more than $25 \%$ of all fatalities involve a rollover. Therefore, it is very important to reduce the rollover risk during vehicle collisions with safety barriers.
Concrete safety barriers (CSBs) have greatly increased the traffic safety since their first usage in New Jersey, U.S., in 1955 [4]. In Europe, they first appeared in Belgium and France in the 1970s as a replacement for the guardrail steel structures [4]. They have long lifetime and require almost no maintenance while offering a relatively high degree of safety. CSBs are designed as median barriers to prevent vehicles crossing into the opposite traffic lanes or as roadside barriers to protect the traffic from roadside obstacles. They are used on major city roads, ring roads, and limited-width highways to reduce the consequences passengers suffer in the event of an accident [5]. These roads are characterised as high-traffic roads, and it is therefore important to ensure fluent and safe traffic while minimising the traffic congestion. In Slovenia as well as in other EU countries, the existing steel safety barriers are often replaced with CSBs due to the limited space available for widening [6]. In some specific situations, the CSBs in combination with other factors such as vehicle type, road and tyre conditions, vehicle speed, impact angle and driver reaction can cause a vehicle rollover, which may have fatal consequences to the vehicle occupants [7]. For that purpose, considerable research effort has 
been devoted to improving and optimising the profile of concrete traffic barriers [8] to [11]. McDevit [8] designed the so-called F-shape concrete barrier in order to improve the safety characteristics of the New Jersey barriers. The need to have a more consistent performance than that of a vertical face concrete wall led to the development of constant slope barriers [8]. Albuquerque and Sicking [12] evaluated the in-service safety performance of safety shaped (New Jersey and F-shaped) and vertical concrete barriers based on rollover propensity and occupant injury severity. It was surprisingly pointed out that vertical concrete barriers are actually safer than shaped barriers. In addition to the profile shape of a CSB, the coefficient of friction between vehicle tyres and a CSB also has an important role in the effective vehicle redirection without causing a rollover crash [13]. However, its influence has not yet been thoroughly examined. Most of the papers do not even mention the used value in their simulation studies [11], [14] and [15], or they simply use constant values [16] to [19]. The publicly available experimental data obtained from full-scale crash testing focusing on a vehicle rollover on a CSB is very limited in quantity and quality and mainly consists of video recordings of experiments without any documented parameter values.

In Europe, CSBs are produced and tested according to EN 1317-2 [20] and EN 1317-5 [21], while the concrete mixture is specified by EN 2061 and EN 13369. However, the above-mentioned standards do not specify the surface roughness or acceptable value of the friction coefficient between the concrete barrier surface and the vehicle tyre. One possible means of reducing the friction coefficient is by using low-friction coatings for concrete [22] to [24]. Although these low-friction coatings are becoming popular, their wider application is limited due to the chemical and impact non-resistance, environmental impact, and their price.

Preliminary data analyses was performed for rollover traffic accidents, which occurred in Ljubljana's ring road between January 1st, 2000 and December 31st 2015 . The data implied a 3 times higher number of vehicle rollovers per kilometre for the northern part of the ring road where median CSBs were installed as compared to the rest of the ring road where steel safety barriers were installed. Although the types of rollover causation in the database were not categorized well enough to allow exclusion of other factors such as road slopes on the sides of the northern part of the ring road, differences in the speed limit, etc., we believe that a significant share of the recorded rollover accidents was caused by CSBs.
The over-involvement of larger vehicles in a rollover, such as SUVs, pickups, and minivan vehicles in fatal crashes, has been well documented in the U.S. in the past studies [9] and [25]. The share of these vehicles in day-to-day traffic in Europe was negligible until recently. However, the vehicle market share presented in Fig. 1 clearly shows that this group of vehicles recorded a nearly $550 \%$ growth in 2015 as compared to 2001 [25]. Their percentage in traffic accidents is expected to increase, also increasing the percentage of rollover accidents. It is thus important to take measures that will prevent the increase in the number of fatalities [26].

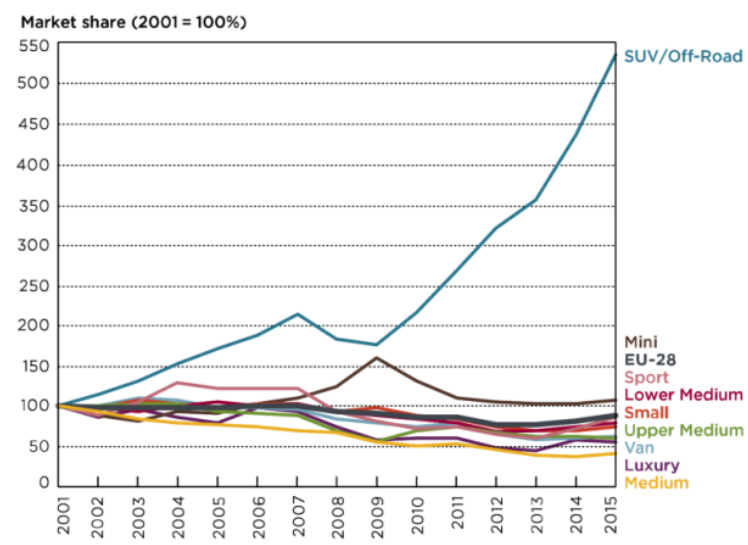

Fig. 1. Vehicle market share according to ICCT [25]

The finite element (FE) method has consistently proved to be a very suitable tool for numerical simulation of a wide range of real-life processes. It simplifies and reduces the cost of examination and product development by allowing precise description of the materials behaviour and the detailed geometry to be incorporated in simulating the reality of the physical process. This study examines the influence of the coefficient of friction between vehicle tyres and the surface of a CSB on the vehicle response after the vehicle-CSB crash scenario. For that purpose, three different finite element vehicle models of Chevrolet C 1500, Suzuki Swift, and Chevrolet Silverado 1500 were used in a numerical crash scenario simulating an impact test with initial conditions taken from the TB11 test case, according to EN 1317-5 [21]. The simulations were performed using the actual measured values of the coefficient of friction between a rubber material and new and aged CSB blocks in dry and wet conditions. 


\section{METHODS}

\subsection{Numerical FE Vehicle Models}

All three vehicles (Fig. 3) used in the numerical examination of this study are publicly available and were successfully validated by the National Crash Analyses Center (NCAC) [27]. For a more detailed description of the FE vehicle models, an interested reader is referred to the validation reports given in references [28] to [32] for Chevrolet C-1500, [29] for Suzuki Swift and [30] for the Chevrolet Silverado 1500. After the introduction of the $\mathrm{FE}$ vehicle models, they were successfully used in different crash analysis studies. Yin [11] used the Silverado 1500 model to optimise the MASH TL-3 concrete barrier, and Kunc at al. [33] and [34] used the Suzuki swift model to compare different protective structures in tunnel emergency-stop-area-walls [33] to [36]. FE vehicle models are also used in a variety of different applications and purposes [14], [36] to [42]. The FE vehicle models used in this study have only limited capabilities in terms of recreating realistic strain- stress response of the wheel suspension elements. The fracture prediction of particular parts due to this is thus not taken into account. Even if the detachment of the suspension components does occur, the forces causing it can still cause a rollover before they reach the magnitudes causing the links between suspension components to fail. It is thus assumed that this has little influence on the simulation results as far as a vehicle rollover is concerned.

In all the numerical simulations in this study, the vehicles were initially placed at an impact angle of $20^{\circ}$ (Fig. 2) in front of the CSB, hitting it with an initial velocity of $100 \mathrm{~km} / \mathrm{h}$. These initial parameters correspond with the TB11 test requirements as described in EN 1317-2 [20]. The friction coefficients between the body pairs involved in contacts used in the simulations are presented in Table 1. The values used are those that, according to measurements (section 2.1 ), can be realistically expected on manufactured CSBs (from 1.0 down to 0.6) and those that are significantly lower but can be achieved and sustained by special treatment [23] and [24] of the surface $(0.6$ down to 0.4 ). The coefficients of friction lower than
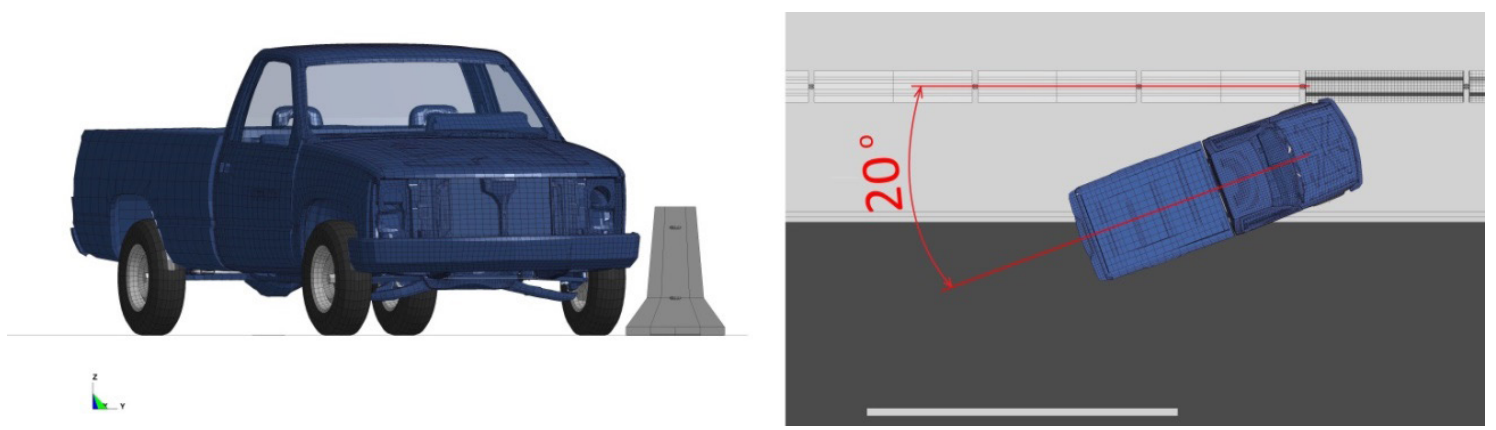

Fig. 2. Initial placement of FE vehicle models before impact (Chevrolet C 1500)
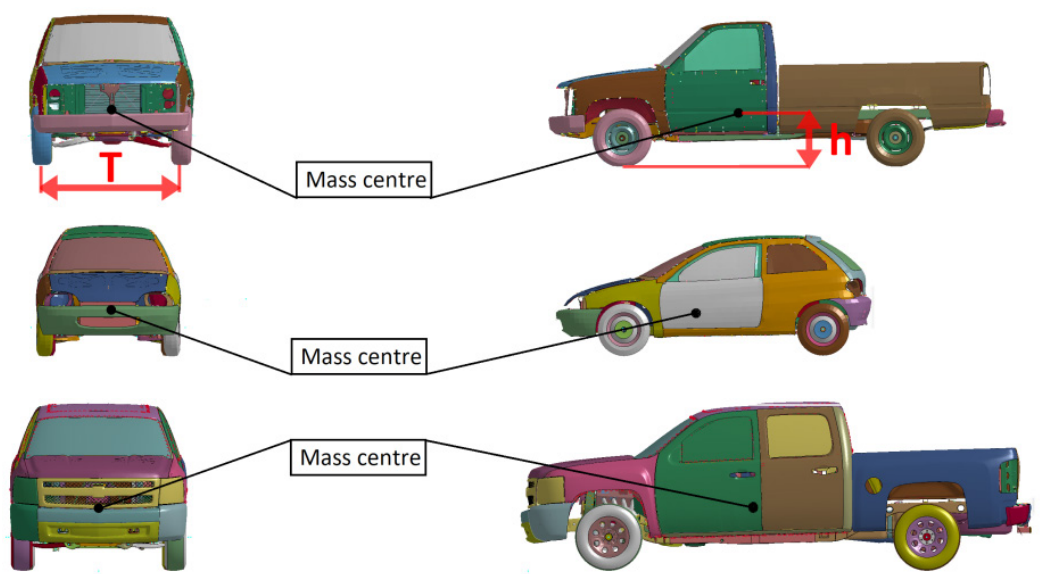

Fig. 3. FE vehicle models 
0.4 are unlikely to be encountered on installed CSBs and were thus not included in the research.

Table 1. Summary of the coefficients of friction used in the numerical models

\begin{tabular}{lcc}
\hline \multirow{2}{*}{ Contact } & \multicolumn{2}{c}{ Friction coefficient } \\
\cline { 2 - 3 } & static $\mu$ & dynamic $\mu \mathrm{D}$ \\
\hline \multirow{3}{*}{ Vehicle tyres - CSB } & 0.4 & 0.3 \\
\cline { 2 - 3 } & 0.6 & 0.5 \\
\cline { 2 - 3 } & 0.8 & 0.7 \\
\hline Vehicle tyres - road surface & 1.0 & 0.9 \\
\hline Vehicle body - CSB & 0.8 & 0.7 \\
\hline Vehicle body - road surface & 0.3 & 0.2 \\
\hline
\end{tabular}

Mass and geometry characteristics of the FE models are summarised in Table 2. The static stability factor $(S S F)$ and static rollover angle $\alpha$ given in Table 2 are calculated using Eq. (1):

$$
S S F=\tan \alpha=\frac{T}{2 h},
$$

where $T$ is the vehicle track width and $h$ is the height of the vehicle centre of mass as per Fig. 3. As can be seen from Table 2, the values of SSF vary between 1.207 for Chevrolet Silverado and 1.305 for Suzuki Swift.

Table 2. Summary of the coefficients of friction used in the numerical models

\begin{tabular}{lccccc}
\hline & \multicolumn{5}{c}{ Characteristic } \\
\cline { 2 - 6 } Vehicle & $\begin{array}{c}\text { Mass } \\
{[\mathrm{kg}]}\end{array}$ & $\begin{array}{c}\text { Track } \\
\text { width } \\
(T) \\
{[\mathrm{m}]}\end{array}$ & $\begin{array}{c}\text { Centre } \\
\text { of mass } \\
\text { height } \\
(h)[\mathrm{m}]\end{array}$ & $\begin{array}{c}\text { Static } \\
\text { stability } \\
\text { factor } \\
(S S F)[-]\end{array}$ & $\begin{array}{c}\text { Static } \\
\text { rollover } \\
\text { angle } \\
(\alpha)\left[{ }^{\circ}\right]\end{array}$ \\
\hline $\begin{array}{l}\text { Chevrolet } \\
\text { C 1500 }\end{array}$ & 2013 & 1.65 & 0.664 & 1.242 & 51.16 \\
\hline $\begin{array}{l}\text { Suzuki } \\
\text { Swift }\end{array}$ & 894 & 1.33 & 0.510 & 1.305 & 52.53 \\
\hline $\begin{array}{l}\text { Chevrolet } \\
\text { Silverado 1500 }\end{array}$ & 2622 & 1.76 & 0.731 & 1.207 & 50.35 \\
\hline
\end{tabular}

\subsection{Median Barrier Anchored}

For the purpose of this study, the FE model of the F-shape CSB profile according to EN 1317-5 [21] also available by NCAC [27] was used. A straight barrier section of $55 \mathrm{~m}$ was built using 18 blocks (Fig. 4) joined together by pinning the embedded loops from two adjacent blocks.

A typical mass of a $3 \mathrm{~m}$ long F-shape profile shown in Fig. 4 is $2000 \mathrm{~kg}$. Although this barrier FE model allows dynamic deflection during vehicle impact, for the purpose of this study it was fixed to the ground. The finite element mesh size of the blocks that are in contact with the vehicle was reduced to $15 \mathrm{~mm}$ on the side of the element.

\section{EXPERIMENTAL}

\subsection{Assessment of Actual Coefficients of Friction between Tyre and Concrete Barrier}

The processes taking place during the phase of the impact between a rubber vehicle tyre and the surface of a concrete barrier involve several relevant physical phenomena [43] and [44]. The authors of [45] classify these phenomena into three classes regarding the mechanism of dissipation of energy: deformation of the bulk of the rubber due to the substrate asperities, very large viscoelastic deformations close to the opening crack tips that may occur resulting in locally very large energy dissipation, and the energy dissipation from shearing a thin contamination film on the rubber surface and/or on the substrate surface. If such a film is not present, direct bonding between the rubber molecules and the substrate, followed by viscoelastic deformation and bond breaking, also contributes to energy dissipation and sliding friction. The authors of the same paper further present the experimental data which show that the combined

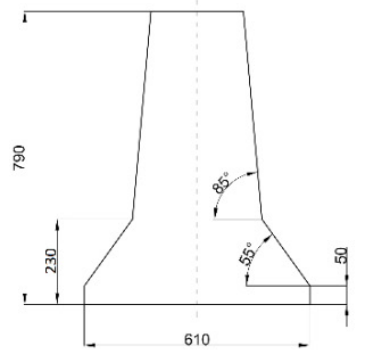

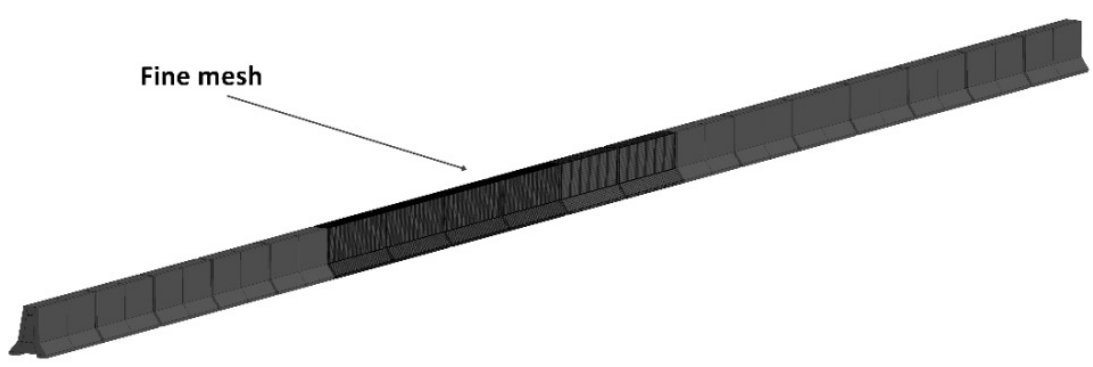

Fig. 4. FE vehicle models 
coefficient of friction due to the described phenomena increases with the relative velocity of the contact surfaces, reaching values close to $\mu=1$ at velocities in the $10^{0} \mathrm{~m} / \mathrm{s}$ to $10^{1} \mathrm{~m} / \mathrm{s}$ range.

To assess the sliding friction coefficient on real concrete barriers, a set of sample tests were performed using a device measuring the pulling force $F_{t}$ versus the device weight $G$ during sliding from still-stand (Fig. 5). Since all barrier faces of a specific CSB have similar surface quality, the measurements were performed on the top face of the barriers, assuming that the results apply to the entire CSB surface.

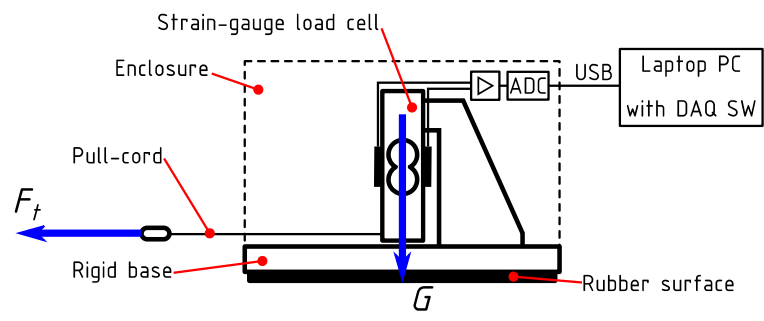

Fig. 5. Schematics of the friction measuring device

The tests were conducted on several concrete barrier blocks with two different types of surface, each in dry and wet conditions. The first type of surface was the rough concrete surface of an aged block (Fig. 6a), while the second type of surface was the smooth surface of a new out-of-mould block (Fig. 6b). The sliding velocities during the tests were in the $10^{-1} \mathrm{~m} / \mathrm{s}$ range.

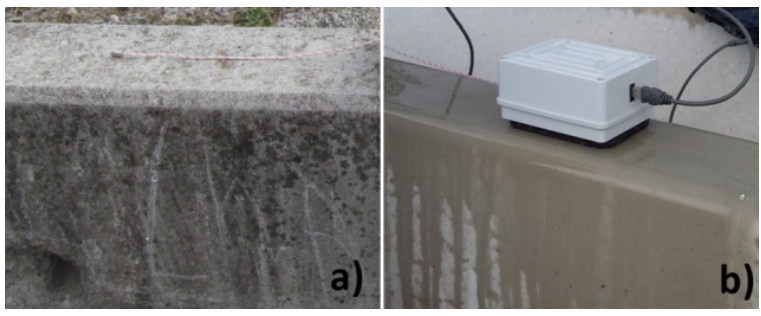

Fig. 6. Measured concrete barrier surfaces: a) rough surface of an aged block in dry condition, b) smooth surface of a new block in wet condition

\section{RESULTS}

\subsection{Pickup Chevrolet C 1500}

Fig. 7 visually shows the simulation results obtained using different coefficients of friction between the vehicle tyres and the CSB. As the coefficient of friction increases, the tyre-concrete grip also increases.

Consequently, the vehicle front-end is raised higher along the side of the CSB (Fig. 7). Additionally, the tyre-CSB coefficient of friction is also important in the second stage of the vehicle-CSB contact at which the rear tyre comes into contact with the CSB (Fig.

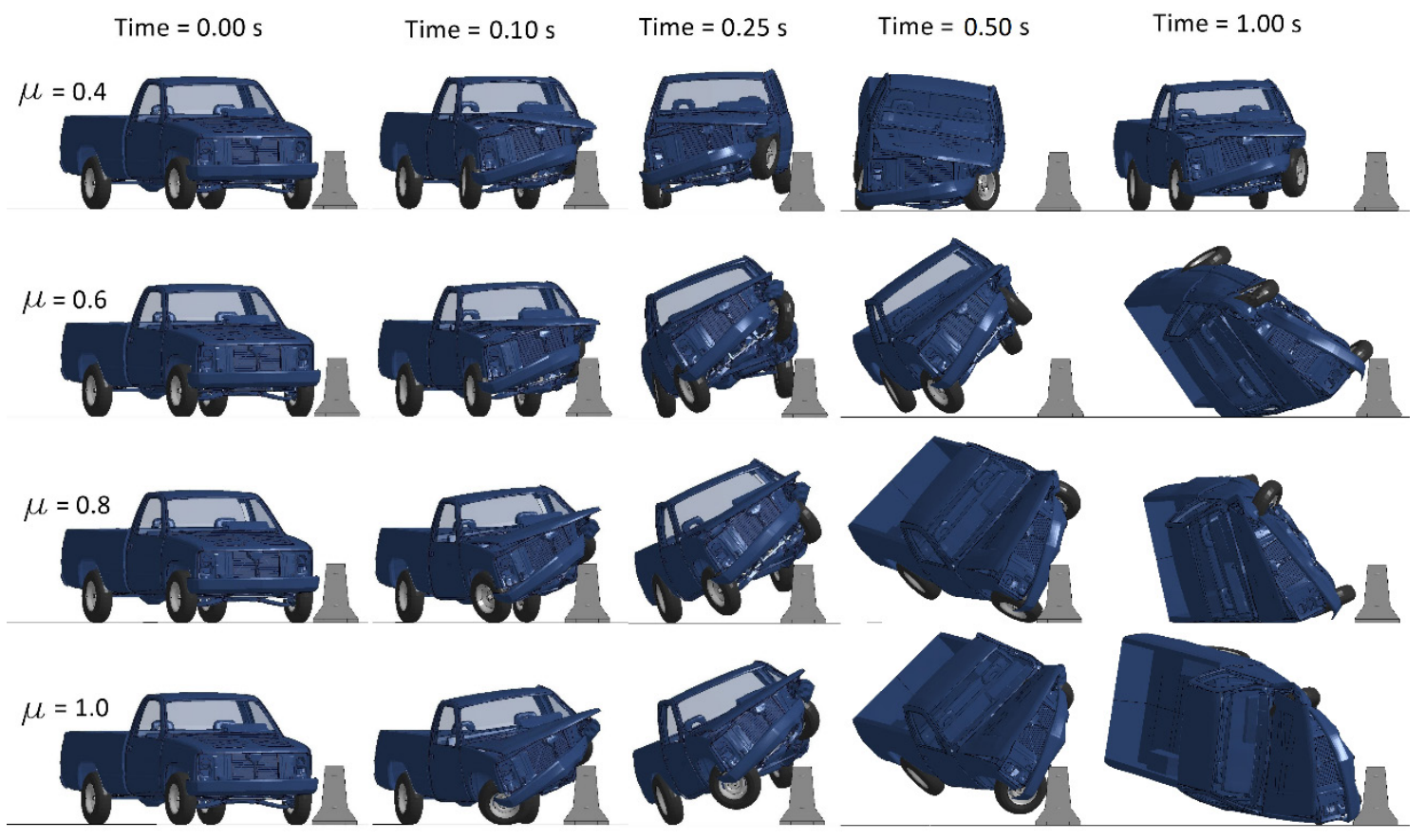

Fig. 7. Pickup Chevrolet C 1500 - CSB contact. Front view 
7, time $0.25 \mathrm{~s}$ ). Depending on the friction coefficient value, the contact could induce or prevent a vehicle rollover. The simulation results show that in the case of low tyre-CSB coefficient of friction $(\mu=0.4)$, the Chevrolet C 1500 is successfully redirected into its driving lane without a rollover, while in all other cases a vehicle rollover occurs. Fig. 8 shows the top view of the simulation results of the vehicle CSB impact at different simulation time frames and different coefficient of friction values.

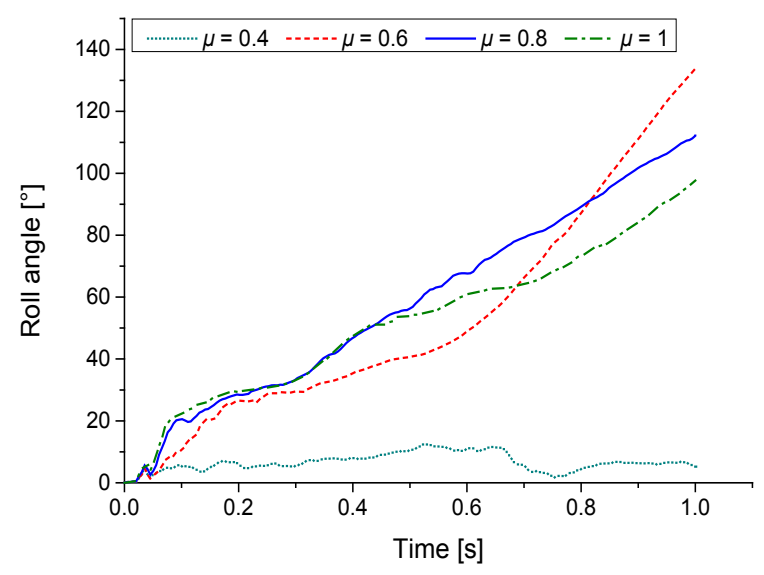

Fig. 8. Roll angle results comparison - Pickup Chevrolet C 1500
The roll angles presented in Fig. 8 were extracted selecting two nodes of the vehicle initially placed at the vertical passing through the vehicle mass centre. From this figure it is also obvious that a vehicle rollover occurs in all cases except in the one with the lowest value of the friction coefficient $(\mu=0.4)$. The roll angles for $\mu=0.6, \mu=0.8$ and $\mu=1.0$ greatly exceed the static rollover angle given in Table 2.

\subsection{Suzuki Swift}

Fig. 9 visually presents the simulation results obtained using different coefficients of friction between the vehicle tyres and the CSB. In this case, no visible vehicle lifting can be noticed.

Fig. 10 presents the roll angles for all cases of the friction coefficient. Although higher roll angle values can be noticed corresponding to higher coefficients of friction, in all the cases the Suzuki Swift vehicle is successfully redirected into its lane without a rollover. The maximal values of the roll angels are significantly below the static roll angle value for the Suzuki Swift vehicle presented in Table 2 .

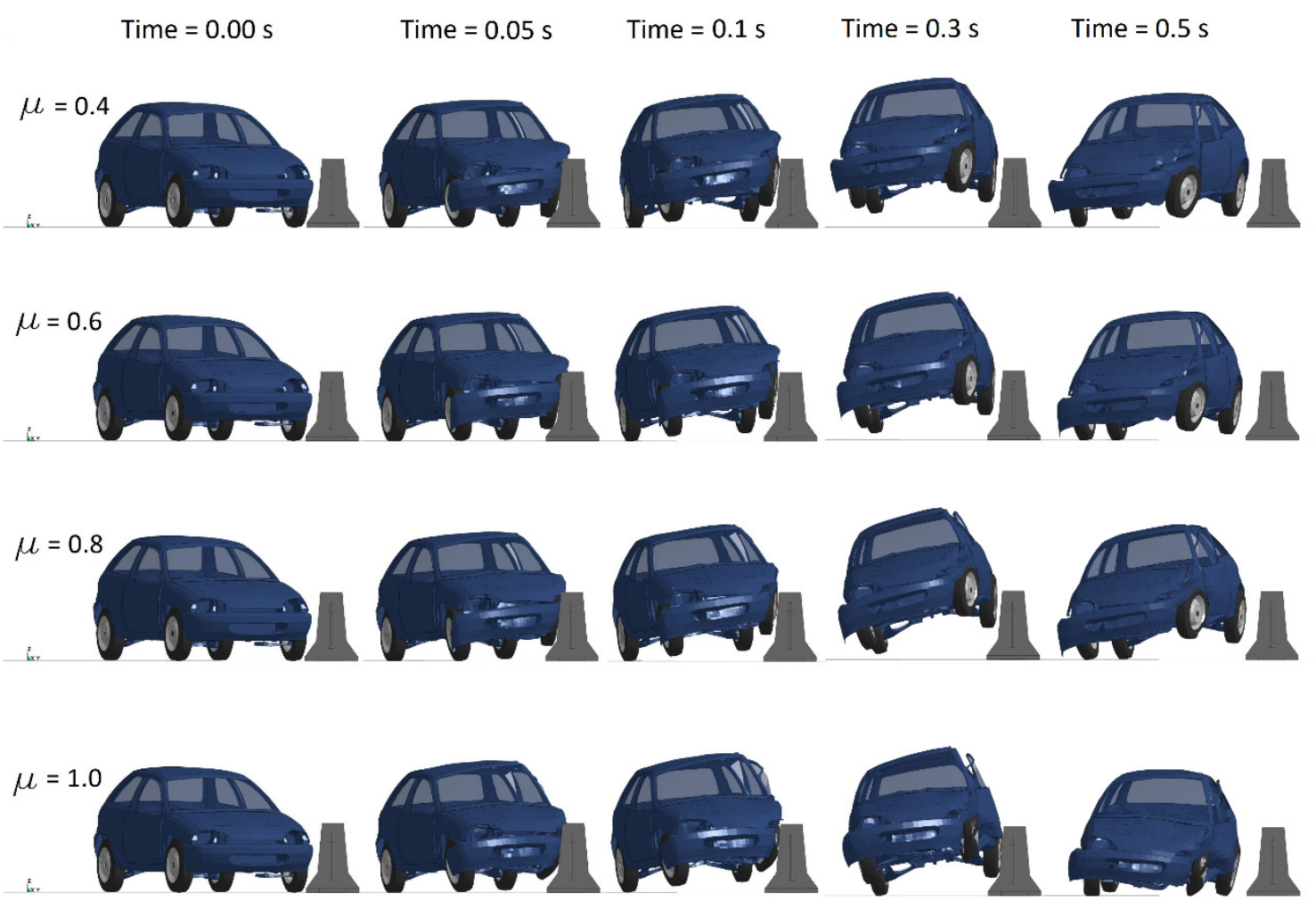

Fig. 9. Suzuki Swift - CSB contact. Front view 


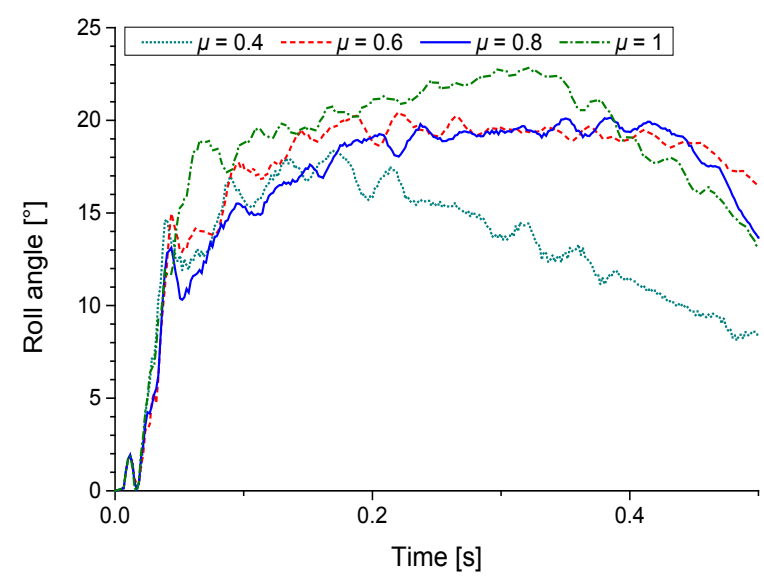

Fig. 10. Roll angle results comparison - Suzuki Swift

\subsection{Pickup Chevrolet Silverado 1500}

Fig. 11 shows the simulation results obtained using different coefficients of friction between the vehicle tyres and the CSB. As can be seen in Fig. 11 , at time $=0.15 \mathrm{~s}$ the tyre-concrete grip increases for higher values of the coefficient of friction, and consequently the vehicle's front is raised higher. Similarly to the Pickup Chevrolet C 1500 vehicle, the tyre-CSB coefficient of friction is also important in the second stage of the vehicle-CSB contact at which the rear tyre comes into contact with the CSB. Depending on the friction coefficient value, it could contribute to the vehicle rollover. In order to reduce the calculation time, different simulation termination times were defined for this model ensuring that the vehicle redirection or rollover was completely covered. Unlike the C 1500 model, the Silverado 1500 vehicle was successfully redirected into its lane for the lower values of the tyre-CSB coefficient of friction $(\mu=0.4$ and $\mu=0.6)$. At $\mu=0.8$, the vehicle rotated mainly around its yaw axis without rolling over (Fig. 11 , Time $=1.20 \mathrm{~s})$. At $\mu=1.0$, a vehicle rollover occurs (Fig. 11, Time $=1.4 \mathrm{~s}$ ).

Fig. 12 presents the roll angles for all cases of the coefficient of friction for the Chevrolet Silverado vehicle. It can be noticed that the roll angles in all cases are well below the static rollover angle presented in Table 2, except in the case of $\mu=1.0$ at which the roll angle increases significantly over the value of the static rollover angle causing the vehicle to roll over.

\subsection{Coefficients of Friction between Tyre and Concrete Barriers}

The results of the measurements are summarized in Fig. 13. The test measurements on the smooth surface of the new out-of-the-mould block show that mean values of the coefficient of the sliding friction on its surface range from 0.69 in dry conditions to 0.70 in wet conditions. The average maximum values for the coefficient of the static friction on the surface of this

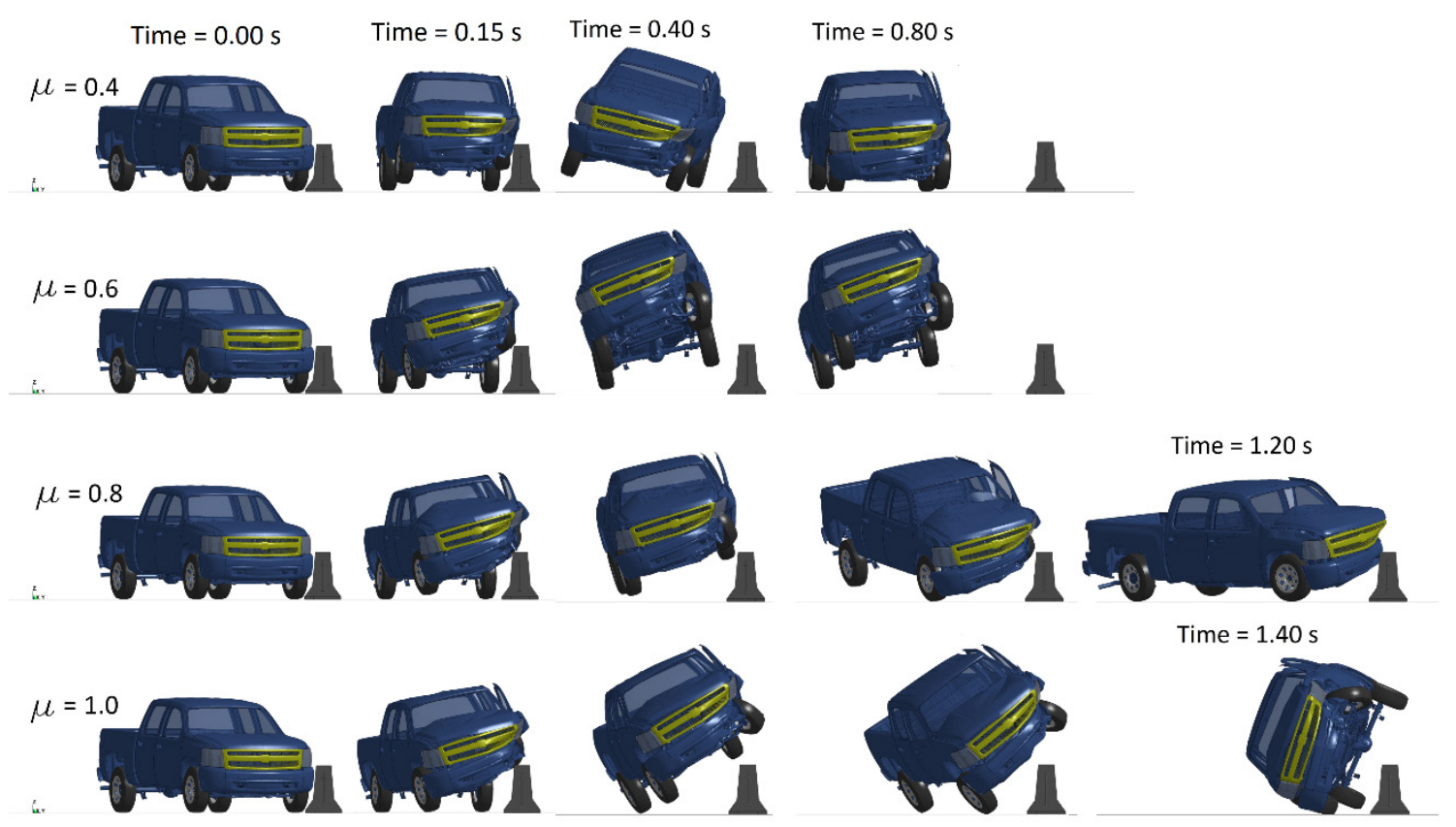

Fig. 11. Pickup Chevrolet Silverado 1500 - CSB contact. Front view 
block range from 0.75 in wet conditions to 0.76 in dry conditions. The test measurements on the rough surface of the aged block show that the mean values of coefficient of the sliding friction on its surface range from 0.75 in wet conditions to 0.80 in dry conditions. The average maximum values for the coefficient of the static friction on the surface of this block range from 0.89 in wet conditions to 0.95 in dry conditions.

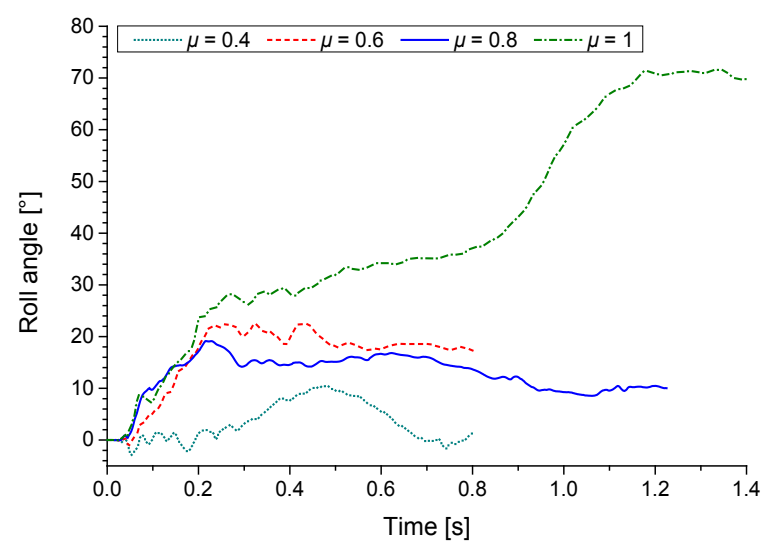

Fig. 12. Roll angle results comparison - Pickup Chevrolet Silverado 1500

The friction coefficients have been measured on installed new and old concrete safety barrier blocks. The new and the old blocks have been exposed to dust and debris. The particles thereof were found to reduce the friction on the dry blocks to some extent, especially on the new blocks. These particles were washed away when a layer of water was applied to the block surface, causing the friction to increase slightly. By doing so, we intended to simulate the natural way of changing the conditions on the block surface, where the dust and debris deposit is periodically washed away with water by rain or by cleaning.

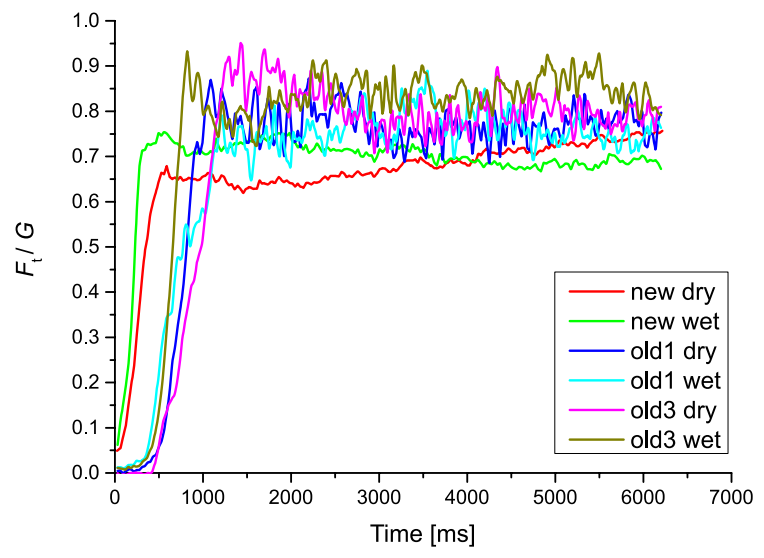

Fig. 13. Measurement results on test surfaces
The results are summarized in Table 3 . The coefficients of friction have been measured with low contact surface relative velocities, meaning that the energy dissipation due to opening crack tips and due to direct bonding between the rubber molecules and the substrate [45] did not occur at all. Considering this, the expected real values of friction coefficients on the contact between the barrier and the vehicle tyre on impact are higher than the measured values and can easily exceed the values found to cause a vehicle rollover.

Table 3. Measured friction coefficient values

\begin{tabular}{lcc}
\hline CSB surface description & avg avg $\mu$ & avg $\max \mu$ \\
\hline smooth surface, new block, dry & 0.69 & 0.76 \\
\hline smooth surface, new block, wet & 0.70 & 0.75 \\
\hline rough surface, aged block 1, dry & 0.77 & 0.87 \\
\hline rough surface, aged block 1, wet & 0.76 & 0.89 \\
\hline rough surface, aged block 2, dry & 0.80 & 0.95 \\
\hline rough surface, aged block 2, wet & 0.84 & 0.93 \\
\hline
\end{tabular}

\section{CONCLUSIONS}

The influence of the coefficient of friction between vehicle tyres and CSB on a vehicle rollover was studied in detail. Additionally, the rubber-CSB coefficient of friction was experimentally determined for aged and new CSB blocks under wet and dry conditions. The results showed that the values of the coefficient of friction can be high enough to cause a vehicle rollover. This is especially true for large vehicles with a higher center of mass, such as pickups, SUVs and minivans, which are becoming increasingly more frequent on the European roads. Apart from the geometry optimization of the CSB profile, it is very important to reduce the coefficient of friction between the surface of a CSB and the vehicle tyre rubber compound in order to reduce the rollover risk in case of a vehicle-CSB contact. To achieve this, different strategies such as reducing the friction coefficient by determining the surface roughness of CSBs or development and application of low friction coatings should be applied in order to reduce the rollover risk for vehicles from this group.

\section{ACKNOWLEDGEMENT}

The research presented in this article has been partly funded by the Slovenian Research Agency as part of the "Modelling in technics and medicine" (code P20109 (C)) research programme. 


\section{REFERENCES}

[1] WHO (2015). Global Status Report on Road Safety 2015. World Health Organization, Geneva.

[2] European Commission - Fact Sheet (2017). 2016 Road Safety Statistics: What is behind the Figures, European Commission La Valette.

[3] Gabler, H.C., Gabauer, D.J. (2007). Opportunities for reduction of fatalities in vehicle-guardrail collisions. Annual Proceedings of the Association for the Advancement of Automotive Medicine, p. 31.

[4] EUPAVE (2012). Concrete Safety Barriers: A Safe and Sustainable Choice. European Concrete Paving Association (EUPAVE), Brussels.

[5] Artimovich, N. (2010). Concrete barriers. FHWA Office of Safety, Roadway Departure Team, Washington.

[6] DARS (2017). Družba za avtoceste v Republiki Sloveniji, from https://www.dars.si/, accessed on 2017-02-12.

[7] Grzebieta, R.H., Zou, R., Jiang, T., Carey, A. (2005). Roadside hazard and barrier crashworthiness issues confronting vehicle and barrier manufactures and government regulators. Proceedings of the $19^{\text {th }}$ International Technical Conference on the Enhanced Safety of Vehicles, Washington.

[8] McDevitt, C.F. (2000). Basics of concrete barriers. Public Roads, vol. 63, no. 5, p. 10-14.

[9] Polivka, K.A., Faller, R.K., Sicking, D.L., Rohde, J.R., Bielenberg, B.W., Reid, J.D., Coon, B.A. (2006). Performance Evaluation of the Permanent New Jersey Safety Shape Barrier-Update to NCHRP 350 test no. 4-12 (2214NJ-2). Midwest Roadside Safety Facility, University of Nebraska-Lincoln, Lincoln.

[10] Zain, M.F.B.M., Mohammed, H.J. (2015). Concrete road barriers subjected to impact loads: An overview. Latin American Journal of Solids and Structures, vol. 12, no. 10, p. 1824-1858, DOI:10.1590/1679-78251783.

[11] Yin, H., Fang, H., Wang, Q., Wen, G. (2016). Design optimization of a MASH TL-3 concrete barrier using RBFbased metamodels and nonlinear finite element simulations. Engineering Structures, vol. 114, p. 122-134, D0l:10.1016/j. engstruct.2016.02.009.

[12] Albuquerque, F.D.B., Sicking, D.L. (2013). In-service safety performance evaluation of roadside concrete barriers. Journal of Transportation Safety \& Security, vol. 5, no.2, p. 148-164, DOI:10.1080/19439962.2012.715618.

[13] Mak, K.K., Sicking, D.L. (1990). Rollover Caused by Concrete Safety-Shaped Barrier, Transportation Research Record, no. 1258, p. 71-81.

[14] Marzougui, D., Zink, M., Zaouk, A., Kan, C.D., Bedewi, N. (2004). Development and validation of a vehicle suspension finite element model for use in crash simulations. International Journal of Crashworthiness, vol. 9, no. 6, p. 565576, D0I:10.1533/ijcr.2004.0311.

[15] Sheikh, N.M., Bligh, R.P., Menges, W.L. (2009). Development and Testing of a Concrete Barrier Design for Use in front of Slope or on MSE Wall. Report 405160-13-1. Texas Transportation Institute, College Station.

[16] Itoh, Y., Liu, C., Kusama, R. (2007). Dynamic simulation of collisions of heavy high-speed trucks with concrete barriers.
Chaos, Solitons \& Fractals, vol. 34, no. 4, p. 1239-1244, D0l:10.1016/j.chaos.2006.05.059.

[17] Thiyahuddin, M.I., Thambiratnam, D.P., Gu, Y.T. (2014). Effect of joint mechanism on vehicle redirectional capability of water-filled road safety barrier systems. Accident Analysis \& Prevention, vol. 71, p. 60-71, D0l:10.1016/J.aap.2014.05.010.

[18] Abraham, N., Ghosh, B., Simms, C., Thomson, R., Amato, G. (2016). Assessment of the impact speed and angle conditions for the EN1317 barrier tests. International Journal of Crashworthiness, vol. 21, no. 3, p. 211-221, D0I:10.1080/135 88265.2016.1164444.

[19] Bielenberg, R.W., Faller, R.K., Reid, J.D., Schmidt, J.D., Pajouh, M.A., Emerson, E. (2016). Development of a retrofit, lowdeflection temporary concrete barrier system. Journal of Transportation Safety \& Security, D0I:10.1080/19439962.20 17.1420717.

[20] EN 1317-2 (2010). Performance Classes, Impact Test Acceptance Criteria and Test Methods for Safety Barriers. European Committee for Standardization, Brussels.

[21] EN 1317-5 (2010). Product Requirements and Evaluation of Conformity for Vehicle Restraint Systems. European Committee for Standardization, Brussels.

[22] Kulkarni, S. (2012). Environmentally Friendly Low Friction Coating for Concrete Barriers, SBIR \& STTR, SBA, Washington.

[23] NanoSonic Anti-Rollover Concrete Barrier Coating (2014). from http://www.nanosonic.com/anti-rollover-concrete-barriercoating/, accessed on 2017-02-12.

[24] Kalenborn Abresist Corp. (2014). KALCOAT 595, from http:// www.abresist.com, accessed on 2017-02-09.

[25] ICCT (2017). European Vehicle Market Statistics: Pocketbook 2016/17. The International Council on Clean Transportation (ICCT), Berlin, p. 118.

[26] Farmer, C.M., Lund, A.K. (2002). Rollover risk of cars and light trucks after accounting for driver and environmental factors. Accident Analysis \& Prevention, vol. 34, no. 2, p. 163-173, D0l:10.1016/S0001-4575(01)00010-0.

[27] NHTSA (2017). National Highway Traffic Safety Administration, US Department of Transportation, Washington.

[28] NCAC (2008). Finite Element Model of C1500 Pickup Truck, National Crash Analysis Center, US Department of Transportation, Washington.

[29] NCAC (2008). Development \& Validation of a Finite Element Model for the 1997 Geo Metro Passenger Sedan, National Crash Analysis Center, US Department of Transportation, Washington.

[30] NCAC (2012). Extended Validation of the Finite Element Model for the 2007 Chevrolet Silverado Pick-Up Truck, National Crash Analysis Center, US Department of Transportation, Washington.

[31] Zaouk, A., Bedewi, N.E., Kan, C.-D., Marzougui, D. (1996). Development and evaluation of a C-1500 pickup truck model for roadside hardware impact simulation. Proceedings of the FHWA Vehicle Crash Analysis Crash Conference, McLean, p. 1-31.

[32] Zaouk, A.K., Bedewi, N.E., Kan, C.-D., Marzougui, D. (1996). Validation of a non-linear finite element vehicle model using multiple impact data. ASME Applied Mechanics Division Publications - AMD 218, p. 91-106. 
[33] Kunc, R., Omerović, S., Ambrož, M., Prebil, I. (2014). Comparative study of European tunnel emergency-stop-areawall protection measures. Accident Analysis \& Prevention, vol. 63, p. 9-21, DOI:10.1016/J.aap.2013.10.020.

[34] Kunc, R., Omerović, S., Ambrož, M., Prebil, I. (2016). How to protect the tunnel SOS niche wall in the event of vehicle impact. Transportation Research Procedia, vol. 14, p. 13051314, D0I:10.1016/j.trpro.2016.05.203.

[35] Teng, T.-L., Liang, C.-C., Tran, T.-T. (2015). Effect of various W-beam guardrail post spacings and rail heights on safety performance. Advances in Mechanical Engineering, vol. 7, no. 11, D0I:10.1177/1687814015615544.

[36] Sheikh, N.M., Bligh, R.P., Albin, R.B., Olson, D. (2010). Application of precast concrete barrier adjacent to steep roadside slope. Transportation Research Record: Journal of the Transportation Research Board, vol. 2195, no. 1, p. 121129, D0l:10.3141/2195-13.

[37] Marzougui, D., Kan, C.D., Opiela, K.S. (2013). Crash test \& simulation comparisons of a pickup truck \& a small car oblique impacts into a concrete barrier. Proceedings of the 13th International LS-DYNA Users Conference, Dearborn.

[38] Hu, B., Li, G.-Q., Sun, J.-Y. (2014). Numerical investigation of K4rating shallow footing fixed anti-ram bollard system subjected to vehicle impact. International Journal of Impact Engineering, vol. 63, p. 72-87, D0l:10.1016/j.ijimpeng.2013.08.006.
[39] Pawlak, M. (2016). The acceleration severity index in the impact of a vehicle against permanent road equipment support structures. Mechanics Research Communications, vol. 77, p. 21-28, D0l:10.1016/j.mechrescom.2016.08.005.

[40] Sassi, S., Sassi, A., Ghrib, F. (2017). Effect of crushable blockouts on a full-scale guardrail system. International Journal of Crashworthiness, vol. 22, no. 1, p. 63-82, DOI:10.1080/13588265.2016.1223525.

[41] Vesenjak, M., Ren, Z. (2003). Computer-aided design of a road restraint barrier. Strojniški vestnik - Journal of Mechanical Engineering, vol. 49, no. 10, p. 509-519.

[42] Borovinšek, M., Vesenjak, M., Ulbin, M., Ren, Z. (2006). Simulating the impact of a truck on a road-safety barrier. Strojniški vestnik - Journal of Mechanical Engineering, vol. 52, no. 2, p. 101-111.

[43] Blackford, J.R., Skouvaklis, G., Purser, M., Koutsos, V. (2012). Friction on ice: Stick and slip. Faraday Discussions, vol. 156, p. 243-254, DOI:10.1039/c2fd00128d.

[44] Persson, B.N.J. (1998). On the theory of rubber friction. Surface Science, vol. 401, no. 3, p. 445-454, D0l:10.1016/ S0039-6028(98)00051-X.

[45] Lorenz, B., Persson, B.N.J., Dieluweit, S., Tada, T. (2011). Rubber friction: Comparison of theory with experiment. The European Physical Journal E, vol. 34, no. 129, p. 1-11, DOl:10.1140/epje/i2011-11129-1. 